\title{
Molecular Targets Involved in the Neuroprotection Mediated by Terpenoids
}

Authors

Laura González-Cofrade ${ }^{1}$, Beatriz de las Heras ${ }^{1}$, Luis Apaza Ticona ${ }^{1,2}$, Olga M. Palomino ${ }^{1}$

Affiliations

1 Department of Pharmacology, Pharmacognosy and Botany, Faculty of Pharmacy, University Complutense of Madrid, Ciudad Universitaria s/n, Madrid, Spain

2 Department of Chemistry, Faculty of Sciences, University Autonoma of Madrid, Cantoblanco, Madrid, Spain

\section{Key words}

antioxidant, radical scavenging, diterpenoids, triterpenoids, neuroprotection, molecular targets, activities

\author{
received April 10, 2019 \\ revised May 29, 2019 \\ accepted June 6, 2019 \\ Bibliography \\ DOI https://doi.org/10.1055/a-0953-6738 \\ Published online June 24, 2019 | Planta Med 2019; 85: 1304- \\ 1315 @ Georg Thieme Verlag KG Stuttgart · New York | \\ ISSN 0032-0943 \\ Correspondence \\ Prof. Olga M. Palomino \\ Department of Pharmacology, Pharmacognosy and Botany, \\ Faculty of Pharmacy, University Complutense of Madrid, \\ Ciudad Universitaria s/n \\ Plaza Ramón y Cajal s/n, 28040 Madrid, Spain \\ Phone: + 34913941767 , Fax: + 34913941795 \\ olgapalomino@farm.ucm.es
}

\section{ABSTRACT}

Natural products and their derivatives represent the most consistently successful source of drug leads. Terpenoids, a structurally diverse group, are secondary metabolites widely distributed in nature, endowed with a wide range of biological activities such as antibacterial, anti-inflammatory, antitumoral, or neuroprotective effects, which consolidate their therapeutic value. During the last decades, and taking into consideration the prevalence of aging-related diseases, research activity into the neuroprotective effects of these types of compounds has increased enormously. Several signaling pathways involved in neuroprotection are targets of their mechanism of action and mediate their pleiotropic protective activity in neuronal cell damage. In the present review, molecular basis of the neuroprotection exerted by terpenoids is presented, focusing on preclinical evidence of the therapeutic potential of diterpenoids and triterpenoids on neurodegenerative disorders. By acting on diverse mechanisms simultaneously, terpenoids have been emphasized as promising multitarget agents.

\section{Introduction}

Neurodegenerative diseases such as AD, PD, stroke, or, more recently, glaucoma are characterized by a progressive loss of structure or function of specialized cells. Taking into consideration the increase in the expectancy of life, these pathologies are the cause of rapidly growing disabilities, with profound social and economic implications throughout the world. Nowadays, there is no effective treatment for addressing the consequences of these neurological disorders, thus, the finding of new valuable medicines is one of the health-care system's priorities.

$A D$, caused by the aggregation of $A \beta$ peptides and neurofibrillary tangles, is the cause of nearly $80 \%$ of neurodegenerative disorders that lead to disturbances of memory and cognitive functions. Its prevalence is around 5 million people at the age of 65 years or older, with an estimated increase up to 13.8 million by 2050 [1,2]. PD is the second most frequent neurodegenerative disease around the world and includes symptoms derived from degeneration of dopaminergic neurons, such as uncontrollable tremors, postural imbalance, and slowness of movement and rigidity. Its incidence is between 10 and 50/100000 person per year, with a prevalence between 100 and 300/100000 population. Both incidence and prevalence increase progressively after 60 years of age [3-5].

In the last years, glaucoma has been included as a neurodegenerative disease, as it causes the loss of functional retinal neurons called RGCs, optic nerve atrophy, and specific visual field defects, which leads to irreversible blindness and is mainly due to high intraocular pressure (IOP). Thus, neuroprotection in glaucoma is de- 


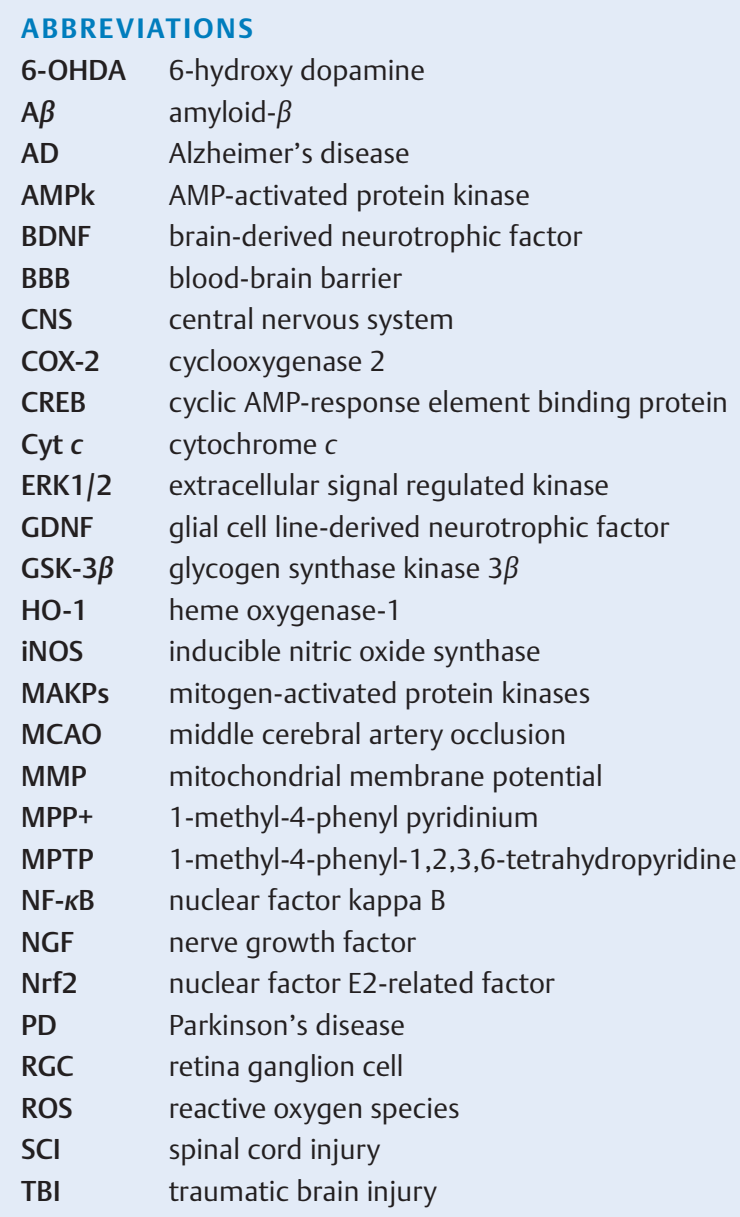

fined as a new therapeutic approach independent of IOP lowering $[6,7]$.

Different pathological mechanisms are known to cause the neurodegeneration process, leading to a wide range of neurological disorders ( $\triangleright$ Fig. 1). The increase in the knowledge of the celIular and molecular events underlying the degenerative process has allowed for identifying new compounds capable of stopping or, at least, slowing the progress of neural deterioration. Identification of new agents pharmacologically active against different human diseases has largely depended on the screening of natural products as secondary metabolites from microbes, fungi, marine organism, higher plants, and animals. Due to their broad spectrum of pharmacological and biological activities, natural products might be possible candidates for the management of such multifactorial pathologies [8-11].

In comparison with the extensive knowledge on polyphenols, terpenoids, also referred as terpenes or isoprenoids, have revealed great interest as new potential therapeutic agents in neurological disorders. In recent years, the molecular mechanisms of these chemical multitarget molecules have been studied, focusing on their actions on neuroinflammation, apoptosis, oxidative stress, and neurofunctional regulation of survival pathways, among others. As multitarget drugs, they may contribute to regulating several alterations associated with a disease, thus helping to over-

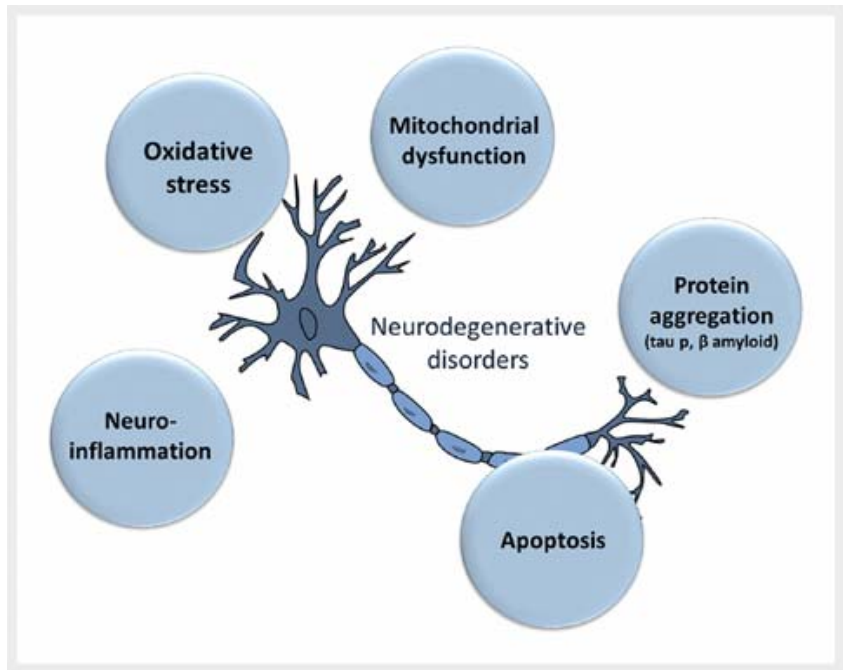

- Fig. 1 Main pathological mechanisms in neurodegenerative disorders affected by terpenoids.

come the drawback of resistance associated with specific target drugs and reducing their range of side effects [12].

This review provides an overview of the most promising neuroprotective diterpenoids ( $\bullet$ Fig. 2 ) and triterpenoids ( $\bullet$ Fig. 3 ) with potential therapeutic value against neurodegenerative diseases. The current knowledge about the molecular mechanisms of action involved in their protective effects is critically discussed.

\section{Molecular Mechanisms Involved in Neurodegeneration}

\section{Neuroinflammation}

Neuroinflammation consists of immune responses relevant to the central nervous system (CNS), carried out mainly by microglial cells but also astrocytes, which are in turn responsible for the neurodegenerative process [13-15]. Aging, metabolic diseases, and viral infections are sources of inflammation that can affect vessels and neurons, leading to neurodegeneration [16]. For all these inflammatory processes, the activation of NF- $\kappa B$ is crucial, as it regulates the expression of multiple genes involved in inflammation, apoptotic cell death, cell survival and neuronal differentiation in the CNS. Microglia activation promotes NF- $\kappa B$ activation, which triggers the transcription of inflammatory and oxidative stress-related genes such as iNOS and COX-2, thus inducing great amounts of proinflammatory mediators such as TNF- $\alpha$, interleukin-6 (IL-6), interleukin-1 (IL-1), and ROS, which could lead to neuronal injury and death $[17,18]$.

Increasing evidence indicates that microglial activation in the CNS can be categorized in two opposite phenotypes: M1, or proinflammatory, and $\mathrm{M} 2$, or anti-inflammatory. Depending on the activated phenotype, microglia can produce either cytotoxic or neuroprotective effects [19]. Several MAPKs such as p38, c-Jun $\mathrm{N}$-terminal kinase (JNK) and ERK are also involved in regulating the production of inflammatory mediators in activated microglia [20]. 


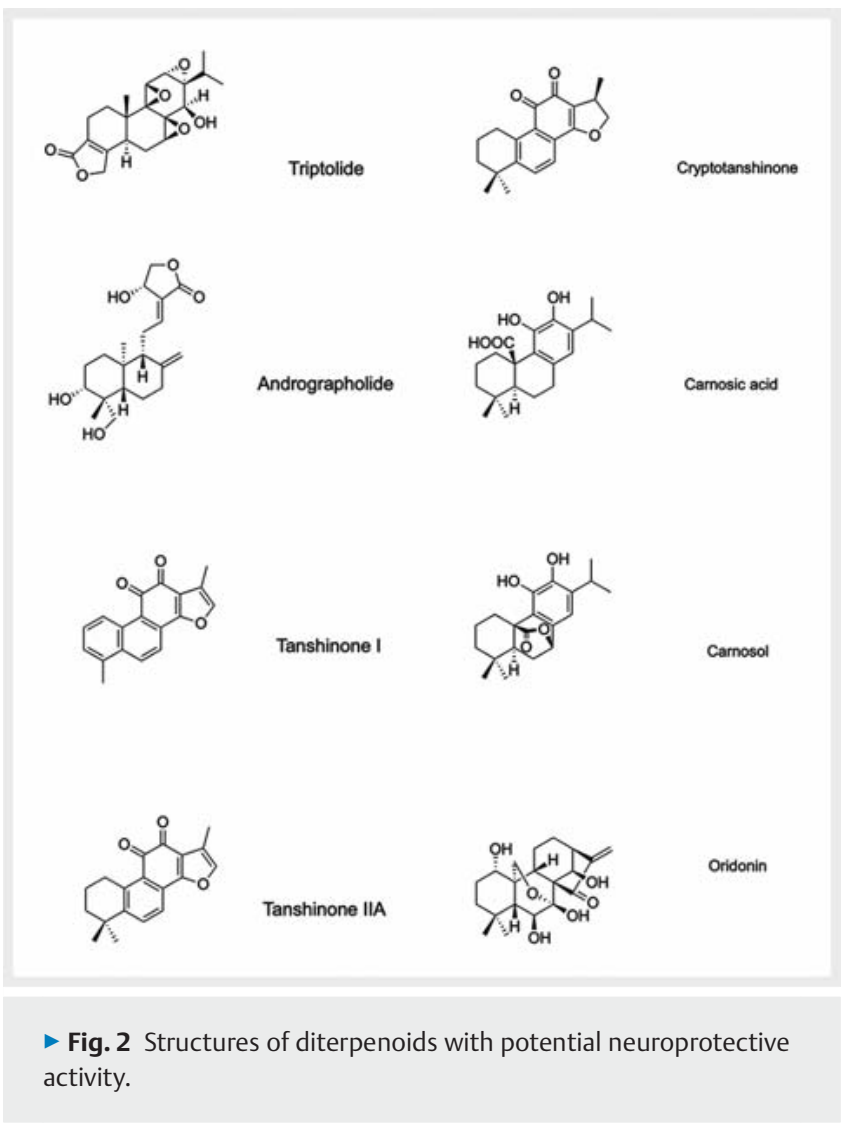

The $A \beta$ deposits, one of the causative factors of $A D$, together with Tau hypothesis, cholinergic and inflammation hypothesis, are considered part of the neuroinflammation process. In this context, direct injection of $A \beta$ into the brain causes activation of microglial cells and neuronal loss [21]. Cytokines stimulate the surrounding astrocyte-neurons to further produce $A \beta 42$ olygomers, forming insoluble and pathological aggregates involving microglia to form clusters at sites of $A \beta$ deposition [22, 23]. Moreover, $A \beta$-induced neurotoxicity has been linked to NF- $\kappa B$ activation $[24,25]$. Therefore, a promising therapeutic approach to attenuate the progression of neurodegenerative disorders might be the inhibition of microglia activation or the reduction of proinflammatory mediator release. Promoting M2 microglia polarization and inhibiting the M1 phenotype could be another strategy to treat neuroinflammation.

\section{Apoptosis}

Apoptosis is a highly regulated programmed cell death pathway. Uncontrolled apoptosis is the main mechanism implicated in neuronal death and the consequent tissue damage in patients with neurodegenerative disorders such as AD, PD, or glaucoma [26, 27].

Two main signaling pathways have been described for the apoptotic process, the extrinsic (death-receptor mediated) and intrinsic (mitochondria-mediated) pathways. Both converge on the activation of death effectors enzymes such as caspases $-3,-6$, and/or -7 . Bc-2 family proteins are key components in the regulation of the intrinsic pathway via monitoring mitochondrial mem-

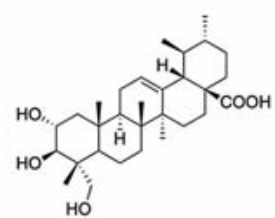

Asiatic acid

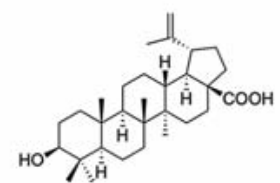

(+)-betulinic acid

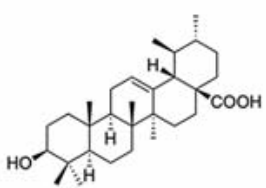

(+)-ursolic acid

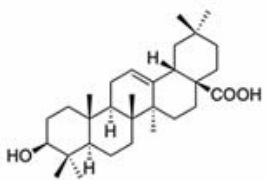

(+)-oleanolic acid

- Fig. 3 Structures of triterpenoids with potential neuroprotective activity.

brane permeability, which leads to the loss of the MMP, and the release of Cyt c, a proapoptotic factor that promotes downstream caspases activation [27-30].

$\mathrm{NF}-\kappa \mathrm{B}$ is also involved in the regulation of apoptosis. It can promote cell survival through the upregulation of the expression of Bcl-2 antiapoptotic factors [31-33].

\section{Survival signaling pathways}

Modulation of neuronal survival/death signal transduction pathways constitutes another approach in the search for effective therapies in neurodegenerative diseases. Experimental evidence indicated that protein kinase B (Akt) is a pivotal survival signal molecule mediating anti-apoptosis and cell survival. Two mitochondrial proteins are phosphorylated following stimulation of mitochondrial Akt, the $\beta$-subunit of ATP synthase and GSK-3 $\beta$, an important and well-known protein involved in the direct induction of tau phosphorylation in AD, which leads to cell death [34]. In addition, the survival phosphatidylinositol 3-kinase (PI3K/Akt) pathway modulates mammalian target of rapamycin (mTOR) kinase activity, which is also altered in neurodegenerative diseases accompanied by cognitive deficits (AD, PD) due to its implication in the regulation of a broad range of cellular processes, including survival, proliferation, growth, and migration of cells $[34,35]$. The fact that the activation of mTOR is related to the presence of soluble $A \beta$ and tau protein reveals the role of mTOR as one of the mechanisms involved in $A \beta$-induced toxicity in $A D$ and indicates the potential of mTOR modulators as effective agents in the prevention of these pathologies [36]. 
Autophagy is an intracellular degradative process in which damaged organelles and long-lived proteins are degraded for maintaining normal cellular homeostasis by forming autophagosomes, a double-membrane vesicle that fuses with lysosomes for the degradation of its contents [37]. Constitutive autophagy clears cytoplasmic components that are useless for cells and is considered a critical cytoprotective pathway. Induced autophagy has been associated with protection against neurodegenerative diseases [38]. The autophagic pathway can be overstimulated by multiple forms of stress, such as hypoxia and ROS, oxygen-glucose deprivation, and cerebral ischemia. A balanced level of autophagy is of paramount importance in neuronal function. Thus, autophagy in the CNS is involved in both survival and death, and its modulation constitutes a new drug target. Signaling pathways and proteins involved are the mTOR kinase complex, AMPk, and Beclin-1 [37, 39, 40].

The PI3K/Akt signaling pathway is essential for the growth and survival of neurons after cerebral ischemia. Activation of this pathway also plays a key role in synaptic activity and normal function, and can promote survival, inhibition of autophagy, and, finally, neuronal protection. The activation of Akt by controlling multiple intracellular signals is able to inhibit neuronal exacerbated autophagy and promote neuronal proliferation and survival [41]. Moreover, MAPKs also regulate various cellular activities, including proliferation, differentiation, apoptosis, survival, inflammation, and innate immunity $[42,43]$. Compromised MAPK signaling pathways have also been found to play key roles in the pathogenesis of neurodegeneration by oxidative stress and cell cycle control, while increased levels of ERK have been found to be related to memory impairment in AD. In this case, JNK is localized with DNA damage and is associated with neurofibrillary pathology, probably its activation being a response to cellular stress. Nonetheless, simultaneous activation of ERK and JNK leads to the initial development of AD $[20,44]$.

Various studies revealed the involvement of ERK and one of its downstream effectors, CREB, in neuronal functions by mediating synaptic events involved in learning, and regulating neuronal plasticity via regulation of protein synthesis, thus playing a major role in memory and cognition [44-46].

\section{Mitochondrial dysfunction and oxidative stress}

Mitochondria are of paramount importance in various essential cellular functions, including metabolism and apoptosis. Due to their high metabolism rate, mitochondria are a source of ROS production and a major target for ROS-induced cellular injury, especially in the brain, which is not adequately able to neutralize ROS effects. Its antioxidant system is characterized by moderate activity of the enzymatic defense constituted mainly by superoxide dismutase (SOD) and gluthathione (GSH) [47].

Another transcription factor responsible for activating the expression of genes with antioxidant activity as a response to oxidative stress from the cytoplasm into the cell nucleus is the Nrf2, which in turn could induce many cytoprotective proteins such as $\mathrm{HO}-1$ [48]. In AD, an upregulation of Nrf2 expression in neurons is detected due to oxidative damage, with the purpose of preventing neuronal toxicity caused by $\mathrm{A} \beta 42$ peptides. Moreover, the ac- tivation of Nrf2 in macrophages and microglia led to a downregulation of the NF- $\kappa \mathrm{B}$-related inflammatory response [49].

The activation and overexpression of the sirtuin protein SIRT1, a nicotinamide adenine dinucleotide (NAD)(+)-dependent histone and protein deacetylase, has been reported to be related to neuroprotection in both acute CNS injuries and neurodegenerative diseases. The AMPK leads to an increase in the NAD level, which in turns enhances SIRT activity through modulation of peroxisome proliferator-activated receptor-gamma coactivator 1 alpha (PGC$1 \alpha$ ), the latter regulating mitochondrial biogenesis. This axis explains the relationship between AMPK/SIRT1/PGC- $1 \alpha$ and the mitochondrial function and energy/redox status in mammalian cells [50].

\section{Other targets: neurotrophic factors and neurogenesis}

Neurotrophic factors (NTFs) or neurotrophins, such as BDNF, ciliary neurotrophic factor (CNTF), GDNF, insulin-like growth factor 1 (IGF-1), and NGF, play key roles in the development and survival of neurons, and maintain axonal and dendritic networks and synaptic plasticity, which is crucial in processes such as learning and memory. The neurotrophins manifest their effects by binding to two discrete receptor subtypes, the Trk (tropomyosin receptor kinase) family of RTKs (receptor tyrosine kinases) and the p75NTR (p75 neurotrophin receptor). It is well known that a deficiency in NTFs exists in classic neurodegenerative disorders [51-53].

In the last years, the role of neurogenesis as a therapeutic strategy for neurodegenerative diseases has been investigated $[5,54]$. The adult brain is capable of generating new neurons from self-renewing and multipotent adult neuronal stem cells in the dentate gyrus in order to replace lost or damaged neuronal cells. In this sense, the Wingless-type MMTV integration site (Wnt) signaling cascade plays a key role by regulating multiple processes in developing the adult brain. In patients suffering neurodegenerative diseases, neurogenesis is impaired. Aging and neurotoxicant exposure strongly antagonize Wnt/ $\beta$-catenin signaling in midbrain dopaminergic neurons and the subventricular zone (SVZ) and lead to the decline of SVZ plasticity and the limited nigrostriatal dopaminergic self-repair in PD. Thus, the finding of a clear mechanism involved in the improvement of endogenous neurogenesis appears to be an ideal approach for the treatment of neurological diseases [54].

\section{Diterpenoids and Triterpenoids as Potential Neuroprotective Agents}

\section{Diterpenoids}

\section{Triptolide}

Triptolide, the main bioactive compound in the Chinese herb Tripterygium wilfordii Hook F (Celastraceae), has attracted extensive attention due to its unique structure as a diterpenoid triepoxide with the ability to cross the BBB and its broad spectrum of biological actions, including neurotrophic and neuroprotective effects after systemic administration [55-57].

Neuroprotection exerted by triptolide has been related to its anti-inflammatory properties, which have been confirmed in ex- 
perimental models of brain and spinal cord injuries. This diterpenoid improved neurological dysfunction in terms of deficit scores and reduced brain infarcted volume in an MCAO rat ischemia-reperfusion model $[58,59]$. Several studies demonstrated that neuroinflammation was reduced by triptolide through the downregulation of NF- $\kappa$ B and MAPK (p38, ERK1/2) signaling pathways [60, 61].

Additional protective mechanisms such as inhibition of apoptosis through the suppression of NF- $K B$ and activation of the $\mathrm{PI} 3 \mathrm{k} / \mathrm{Akt} / \mathrm{mTOR}$ signaling pathways have also been confirmed in MCAO models after triptolide administration, resulting in attenuation of cerebral ischemia $[59,61,62]$. This diterpenoid has also emerged as a modulator of autophagy through the upregulation of Beclin-1 [63].

Furthermore, triptolide also demonstrated an in vivo therapeutic effect for TBI. It suppressed the increase of TBI induced in contusion volume, cell apoptosis, edema, and the levels of various proinflammatory mediators in the brain [64], with improvement of neurobehavioral outcomes regarding motor, sensory, reflex, and balance function.

Neuronal cytotoxicity induced by the abnormal deposition of proteins such as $\alpha$-synuclein and amyloid beta-peptide (A $\beta$ 25$35)$, in $\mathrm{PD}$ and $\mathrm{AD}$ experimental models, respectively, was protected by triptolide by acting as a potent autophagy inducer in neuronal cells $[60,65]$. Attenuation of immune-inflammatory responses of this diterpenoid on dendritic spines was observed after bilateral microinjection of aggregated beta-amyloid protein Ab140 into the hippocampus in a rat model of AD [66].

As previously mentioned, inflammatory response following activated microglia is also reported to occur in diseases as PD and glaucoma. Protective effects of triptolide on dopaminergic neurons damage were mediated by the inhibition of proinflammatory mediators from activated microglia, as demonstrated in MPP+-induced hemiparkinsonian rats [67], with an improvement in behavioral disabilities. Additionally, preclinical glaucoma studies have demonstrated that this diterpenoid improved RGC survival through the suppression of microglia activation and proliferation in glaucoma rat models $[68,69]$. Besides having protective effects via the microglia, triptolide exhibited in vitro neurotrophic activity via stimulation of the production and release of NGF in astrocytes [70].

Despite the promising effects of triptolide on neurodegeneration, poor aqueous solubility and systemic toxicity were the main causes that limited preclinical development and clinical translation of the compound. The synthesis of new derivatives with enhanced water solubility and reduced toxicity has focused a great interest in this area. Key pharmacophores such as the epoxy and C-14-hydroxyl groups and their role on its in vitro neuroprotective action have been explored. Epoxy groups, but not the $14-\beta-\mathrm{OH}$ group, were confirmed to be essential for the anti-neuroinflammatory action of triptolide derivatives [71].

\section{Andrographolide}

Andrographolide is a natural labdane diterpenoid from the aerial parts (mainly leaves) and roots of Andrographis paniculata (Burm. f.) Nees (Acanthaceae) [72,73].
Andrographolide was able to target several mechanisms involved in cerebral ischemia. Its neuroprotective activity was linked to its ability to inhibit neuroinflammation and oxidative stress [73-75]. Both microglial activation and the expression of proinflammatory factors were significantly inhibited by this diterpenoid via attenuation of PI3K/AKT-dependent NF-KB and hypoxiainducible factor 1- $\alpha$ activation [74]. Andrographolide also provided protection against oxidative injury and neurological deficits via increasing Nrf2-HO-1 expression through p38 and ERK-MAPK regulation $[76,77]$, as confirmed in rat primary astrocytes [78]. Therefore, these findings suggested that this diterpenoid could improve neurobehavioral function by inhibiting NF- $\kappa$ B and MAPK signaling pathways.

Additional protective mechanisms such as regulation of cell apoptosis, autophagy, and S100B expression (a compound produced mainly by astrocytes with a neurotrophic effect, which in turns reduces hypoxia injury) have been reported for andrographolide. In vitro, this diterpenoid attenuated the apoptotic process in hypoxia-injured astrocytes by reducing proapoptotic proteins such as caspase- 3 and -9 and Bax and increasing Bcl- 2 expression. Andrographolide increased Beclin-1 expression, together with other markers of autophagy such as LC3II, and, in parallel, decreased the formation of autophagosomes. As for the autophagy regulation, the neurotrophic effect was mediated by the JNK pathway [79].

The in vivo therapeutic potential of andrographolide has been confirmed in animal models of AD $[80,81]$. When tested in the Octodon degus (degu) model associated with age, this diterpenoid exerted several beneficial effects, like recovery of spatial memory and learning performance, recovery of synaptic basal transmission, partial or complete protection of certain synaptic proteins, and a specific neuroprotective effect, including the reduction of the phosphorylated Tau protein and amyloid beta aggregate maturation [80]. Andrographolide inhibited certain pathways related to inflammation and apoptosis, including Akt, NF- $K B$, and MAPK signaling. Beneficial effects were also demonstrated in synaptic transmission and recovery of memory along with a reduction in Tau phosphorylation in an $A D$ transgenic mouse model with $A \beta P P$ and PS-1 mutant transgenes (A $\beta$ PP/PS1) [81].

On the other hand, a reduction in the dopaminergic neurodegeneration mediated by the inhibition of microglia activation, a mechanism involved in PD, has been described for this labdane diterpenoid [82]. Andrographolide stimulated neurogenesis in the adult hipoccampus by acting as a competitive inhibitor of GSK$3 \beta$, a key enzyme of the $\mathrm{Wnt} / \beta$-catenin signaling cascade [83].

Apart from the proven beneficial activities shown by this diterpenoid, some andrographolide derivatives, such as the andrographolide-lipoic acid conjugate AL-1 or andrographolide sulfonate have also demonstrated marked neuroprotective effects in animal models of PD and AD [84-86].

\section{Tanshinones}

Tanshinones are abietane diterpenoidsisolated from different Salvia species, especially Salvia miltiorrhiza Bunge (Lamiaceae) (red sage, Chinese sage, tan shen or Danshen [87]), with tanshinone I, tanshinone IIA, and cryptotanshinone being their major bioactive constituents. Tanshinones have been reported to exert beneficial 
activity in AD, cerebral ischemia/reperfusion injury, and even glioma [87].

Neuroprotective effects of tanshinone I have been mainly related to its antioxidant activity through the Nrf2/ARE signaling pathway. For instance, tanshinone I treatment suppressed hypoxic-ischemic brain damage (HIBD)-induced neuronal death and oxidative stress, thereby ameliorating myodynamia and motor abilities, as well as spatial learning and memory in neonatal rats after HIBD, an animal model of neonatal hypoxic-ischemic encephalopathy [88]. Protection against ischemic damage causing neuronal death in the gerbil hippocampal CA1 region has also been described via the maintenance of antioxidant status and the increase of neurotrophic factors (BDNF and IGF-I) [89].

Activation of the expression of the nuclear level of $\mathrm{Nrf2}$ and its transcriptional activity by tanshinone I have also been reported in PD animal models [90]. This diterpenoid protected SH-SY5Y cells against 6-OHDA-induced neurotoxicity, thus ameliorating dopaminergic neurodegeneration in the striatum in mice. Furthermore, tanshinone I was able to modulate the immune response of microglia through inhibition of the expression of M1 proinflammatory factors (NO, TNF- $\alpha$, IL- $6, \mathrm{IL}-1 \beta$ ), but not the expression of M2 anti-inflammatory factors, and also prevented nigrostriatal dopaminergic neurodegeneration in an MPTP mouse model of PD [91].

Regarding tanshinone IIA, the major constituent of Danshen, several studies demonstrated the therapeutic efficacy of this diterpenoid against cerebral ischemia/reperfusion injury and traumatic injury of the spinal cord in rats, with marked improvement of neurological deficits $[92,93]$. Tanshinone IIA exerted anti-inflammatory, antiapoptotic, and antioxidant actions and promoted neuronal survival [94]. Tanshinone IIA reduced the brain infarct area and BBB permeability in rat models of MCAO. Early protective effects of this terpenoid in acute ischemic stroke in rats were associated with the induction of the CREB signaling pathway, which plays a pivotal role in neuronal survival [95]. Protective effects were also partly mediated by its anti-inflammatory effect on macrophage migration inhibition factor (MIF) expression, NF- $\kappa$ B activity, the release of proinflammatory cytokines (TNF- $\alpha$ and IL-6), and the reduction of neutrophil infiltration together with antiapoptotic effects by the reduction of caspase- 3 expression and increased B-cell lymphoma 2 (bcl-2) protein expression in the ischemic cortex [92]. Nrf2 activation by tanshinone IIA treatment increased the content of antioxidant enzymes and reduced the generation of oxidative products after focal brain ischemia [96]. All these findings suggest great potential of tanshinone IIA in ischemic brain damage.

In addition, tanshinone IIA also proved to be an effective treatment for $\mathrm{SCl}$, as it provided neuronal protection against apoptosis and attenuated the inflammatory and oxidative stress responses in rats $[93,97]$. Synergistic neuroprotective effects in combination with methylprednisolone have also been demonstrated with this diterpenoid, leading to improved motor function after SCI.

The therapeutic potential of this diterpenoid in AD and PD was confirmed by in vivo assays $[98,99]$. Both tanshinone IIA and cryptotanshinone alleviated memory decline in a nongenetic mouse model of $A \beta 1-42$-induced AD. Suppression of reactive gliosis and neuroinflammation was evidenced by reduction of inflammatory markers (COX-2 and iNOS) as well as inhibition of the NF- $\kappa$ B signaling pathway. Furthermore, promotion of survival of nigrostriatal dopaminergic neurons in the MPTP mouse model of PD was observed with both compounds through suppression of microglial activation and reduced expression of NADPH oxidase and iNOS [99].

\section{Other Diterpenoids}

\section{Oridonin}

Oridonin is an ent-kaurane diterpenoid isolated from the Chinese herb Isodon rubescens (Hemsl.) H. Hara (Lamiaceae). The therapeutic potential of this diterpenoid in neuroprotection has been recently reviewed [100]. It was able to interact with target proteins and signaling pathways that regulate several cellular responses, including apoptosis, autophagy, inflammation, and neuroinflammation [101]. Oridonin reduced microglia activation and $A \beta 1-42$ induced neuroinflammation through inhibition of the NF$\kappa \mathrm{B}$ pathway and activation of the BDNF/TrkB/CREB and Nrf2 signaling pathways. Additionally, this diterpenoid upregulated the expression of the neurotrophic factor NGF. After oral administration of oridonin, a significant attenuation in memory and cognitive deficits was observed in a mice model with $A \beta 1-42$-induced AD.

\section{Carnosic acid and carnosol}

Carnosic acid and carnosol are the major abietane diterpenoids found in Rosmarinus officinalis L. (rosemary) (Lamiaceae). Protective effects upon neuronal cells have been linked with the intrinsic antioxidant capacity of both diterpenoids by activation of signaling pathways that modulate antioxidant defenses in brain cells, such as the Nrf2/ARE pathway [102]. In vitro, carnosic acid prevented apoptosis by activation of the PI3K/Akt/NF-KB axis and reduction of phosphorylation of MAPKs. In addition, carnosic acid downregulated the expression of inflammatory markers such as COX-2 in hypoxic PC12 cells. An indirect antioxidant effect by regulating $A \beta$ peptide synthesis was also demonstrated.

It was shown that carnosic acid penetrated the BBB and exerted protective effects by acting on redox balance and neuroinflammation. It was demonstrated to be an effective treatment against ischemic injury in an experimental MCAO mice model, preventing an increase in infarct volume. This diterpenoid also protected the rat hippocampus from amyloid- $\beta$-induced lesions in an experimental model of AD. Additionally, an improvement in the behavior was reported after oral administration in a rat model of PD induced by 6-OHDA $[102,103]$.

\section{Triterpenoids}

\section{Asiatic acid}

Asiatic acid is a pentacyclic triterpenoid isolated from Centella asiatica (L.) Urb. (Apiaceae). Mechanisms involved in neuroprotection exerted by this terpenoid have been revised and clearly demonstrated asiatic acid acting as a multitarget agent [104, 105].

Asiatic acid exerted beneficial effects in stroke models. It improved cell viability and MMP in HT-22 hippocampal neuronal cells exposed to oxygen-glucose deprivation. In vivo studies in several models of brain stroke, including the classical MCAO, have shown that oral administration of asiatic acid significantly reduced infarct 
volume and improved neurological functions through reduction of BBB permeability and inhibition of mitochondrial Cyt $c$ release [106]. Furthermore, these effects on mitochondrial dysfunction amelioration were confirmed after intravenous administration of asiatic acid [107]. Synergistic effects with a low dose of tissue plasminogen activator (t-PA) led to a reduction of the infarct volume and to an improvement in neurological outcomes [108].

Asiatic acid is also a potential agent for treating $A D$, dementia, and cognitive deficits. Antiapoptotic and antioxidant effects were shown in vitro, with the ability to attenuate cognitive deficits in a dementia model of monosodium glutamate-treated neonatal mice. Antioxidant effects were related to an increase in PGC- $1 \alpha$ and SIRT1 protein expression and the restoration of MMP, SOD activity, and glutathione levels [109].

Regarding AD, experimental evidence supports neuroprotection by asiatic acid acting on multiple targets (amyloid- $\beta$ formation, apoptosis, oxidative stress, cholinergic deficit). In primary rat cortical neurons, asiatic acid modulated numerous enzymes associated with the formation of $A \beta[110]$ and also reduced mitochondria-dependent apoptosis by decreasing ROS production, maintaining MMP levels, and, finally, downregulating proapoptotic proteins and dephosphorylation of ERK1/2 [111]. In addition, activation of the AKT/GSK-3 $\beta$ signaling pathway has also been reported [112]. Further evaluation by an aluminium chloride-induced model of $A D$ revealed asiatic acid as a protective agent against $A \beta$ formation and neuroinflammation [113].

Moreover, asiatic acid was able to enhance Notch1 and doublecortin (DCX) levels, which were strongly correlated with increased neurogenesis in the hypocampal dentante gyrus and, thus, a marked improvement in the spatial working memory in adult rats [114].

Antioxidant and antiapoptotic effects were also involved in the therapeutic potential of asiatic acid in PD. These effects were observed in rotenone-induced apoptosis in SH-SYS5Y cells $[115,116]$ and further confirmed in MPTP-treated mice, as an in vivo model of PD [117]. After oral administration of asiatic acid, an increase in striatal glutathione levels, decrease in ROS production, and modulation of the apoptotic process, together with anti-inflammatory effects, were observed. These effects could be explained by the suppression in the striatal expression of toll-like receptors (TLRs) and NF-KB [117]. Asiatic acid also improved dopamine striatal levels, thus ameliorating dopaminergic neurodegeneration, along with a marked neurotrophic effect by increasing the neurotrophins BDNF and glial cell line-derived GDNF [117] and its tyrosine kinase receptors (TrKB) [118]. Survival signaling pathways such us MAPKs and PI3K/Akt/mTOR were also involved in the neuroprotective effect offered by asiatic acid on dopaminergic neurons in this PD model.

Interestingly, a recent study pointed out asiatic acid as an antiglaucoma agent due to its antiapoptotic properties [119]. The loss of RGCs and the apoptotic markers (Bcl-2, Bax, and caspase-3) were reduced after intravitreous injection of asiatic acid in glaucomatous rats, which lead to an amelioration of retinal dysfunction.

\section{Betulinic acid}

Betulinic acid, a lupane-type pentacyclic triterpenoid, is found mainly in the bark of Betula species (birch trees) (Betulaceae), but is widely present in the plant kingdom. It has shown several biological properties $[120,121]$. As reported for other pentacyclic triterpenoids, multiple molecular mechanisms are involved in their neuroprotective effect, such as the reduction of neuroinflammation, oxidative stress, and apoptosis, the activation of neuronal survival signaling pathways, and the stimulation of neurogenesis.

Treatment with betulinic acid protected against cerebral ischemia-reperfusion injury in the MCAO model by the downregulation of NADPH oxidase 2 (NOX2), iNOS expression, and different isoforms of neuronal nitric oxide synthase (nNOS). It also enhanced blood flow by upregulating endothelial nitric oxide synthase (eNOS) expression and decreasing ROS production [122]. In addition, recent data indicated that the downregulation of NADPH oxidase 4 (NOX4) expression in the ischemic hemisphere is also involved in the reduction of infarct volume and neurological deficit carried out by betulinic acid [123]. Antioxidant effects were also confirmed in both rat hippoccampal neuron culture and rat models of AD and vascular dementia [124-126].

Moreover, betulinic acid also influenced neuroinflammation by the reduction of proinflammatory cytokine levels in the hippocampus, with improvement of memory damage and cognitive decline [125]. Interestingly, it has also been shown to promote M2 anti-inflammatory phenotype polarization of lipopolysaccharide (LPS)-stimulated BV-2 microglial cells and to inhibit M1 proinflammatory phenotype. This study was carried out via calmodulin-dependent protein kinase $\beta$ (CaMKK $\beta$ )-dependent AMPK activation, which was further confirmed in mice brains treated with betulinic acid [127].

In addition, this triterpenoid has been shown to increase survival in hippocampal neuronal rat cells through the activation of the PI3K/Akt pathway and reduction of apoptosis [124]. Finally, betulinic acid administration significantly ameliorated cognitive deficits in vascular dementia by increasing CAMP/cGMP and BDNF hippocampal levels through CREB phosphorylation [126].

\section{Other Triterpenoids}

Ursolic acid

Ursolic acid, a natural pentacyclic triterpenoid acid found in several species of the Oleaceae family, protected against ischemic injury by activating the nuclear translocation of the Nrf2 protein and increasing the expression of $\mathrm{HO}-1$ and $\mathrm{AKT}$ in the mouse brain $[128,129]$.

\section{Oleanolic acid}

Oleanolic acid is a ubiquitous triterpenoid found in medicinal plants such as Olea europaea $L$. (Oleaceae), Calendula officinalis L. (Asteraceae), and Viscum album L. (Viscaceae). The protective role of oleanolic acid and its derivatives has been studied using different in vitro and in vivo models of cerebral ischemia, such as oxygen-glucose deprivation in neuronal primary cultures and global or focal ischemia in rodents. Protective effects have been associated with a reduction of the cellular oxidative stress response via the upregulation of Nrf2 and inhibition of NF- $\kappa \mathrm{B}$ [130]. 


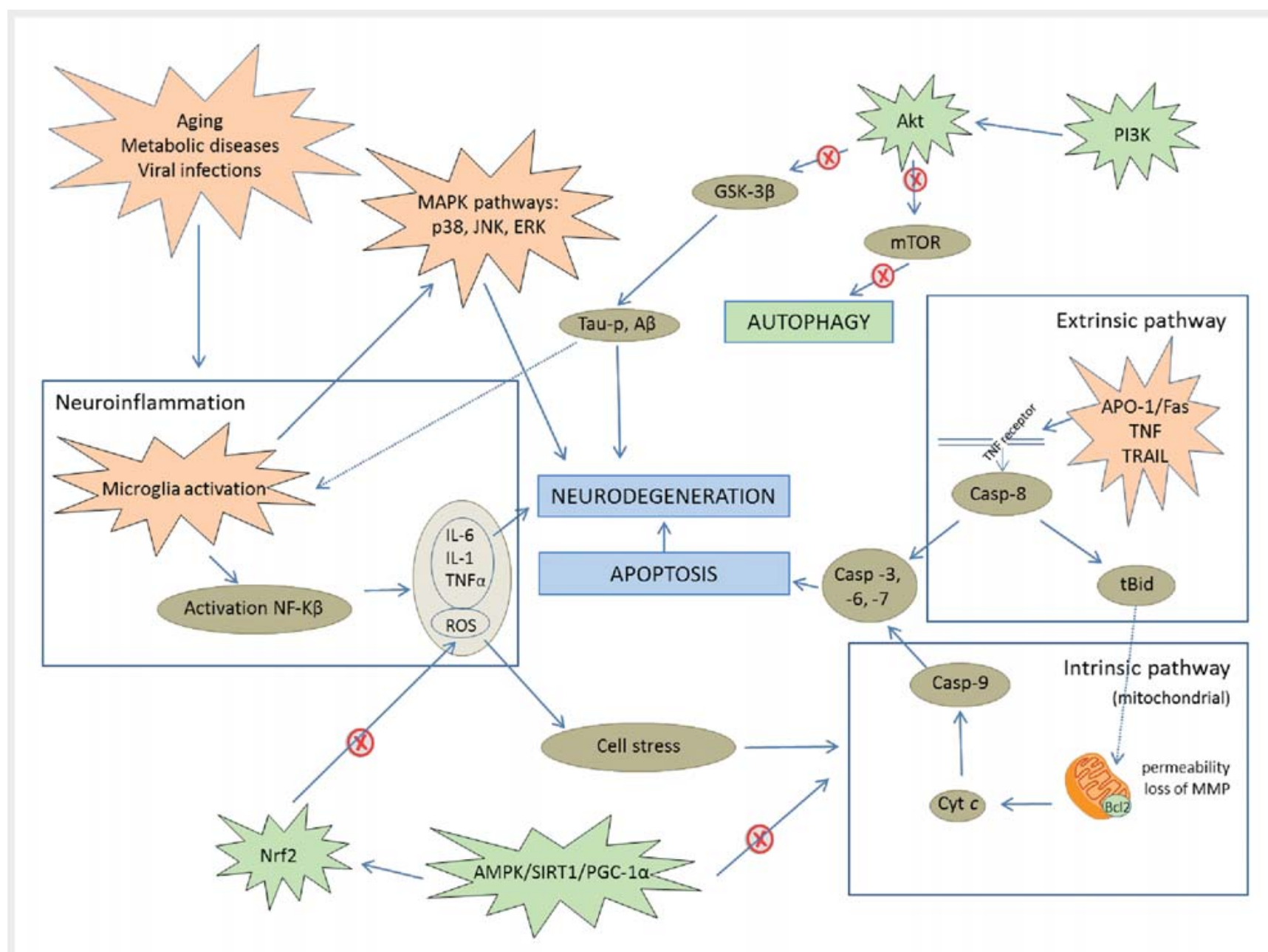

- Fig. 4 Molecular mechanisms involved in the terpenoids neuroprotection.

\section{Summary and Future Perspectives}

Neuroprotective agents represent an exciting area of potential future interventions for many diseases. Currently, no pharmacologically effective treatment is available to block or cure the progression of neurodegenerative diseases. In this context, the discovery of new neuroprotective drugs is an area for extensive research.

Natural products and, among them, terpenoids have emerged as a promising group of potential agents in neuroprotection, supported by their structure diversity and results from preclinical studies. Terpenoids protect against neuronal cell damage and death, acting on multiple molecular targets that regulate several cellular responses. In this review, different protein targets and signaling pathways modulated by these natural products have been discussed ( $\triangleright$ Fig. 4).

Traditionally, the clinical use and efficacy of terpenoids has been hampered by several limitations that have greatly hindered their development as drug candidates due to poor aqueous solubility, a narrow therapeutic window, systemic toxicity, and low target efficacy. These factors are the main limitations with regard to the development of new formulations for clinical use. To solve these obstacles, various approaches have been made in terpenoid research during the last decades. Advancements were done via the structural modifications of lead candidates to obtain more polar derivatives, yielding a great amount of information regarding the structure-activity relationship. Apart from structure modifications, the exploration of new nanoscale drug delivery systems that would enhance penetration of terpenoids into the brain have also been explored. Recently, novel nanoformulations of diterpenoids and triterpenoids based on suitable drug delivery systems have been developed with successful brain-targeted delivery, thus offering a significant improvement in the future application of terpenoids in neurological diseases.

In conclusion, in view of the pleiotropic effects on cell death and survival, terpenoids represent a promising chemical group with potential beneficial effects in neurological diseases. However, further studies, including clinical trials, should be conducted to develop in-depth knowledge of these compounds that would likely help for translational outcomes. 


\section{Conflict of Interest}

The authors declare that they have no conflict of interest.

\section{References}

[1] Anand R, Gill KD, Mahdi AA. Therapeutics of Alzheimer's disease: Past, present and future. Neuropharmacology 2014; 76 Pt A: 27-50

[2] Alzheimer's Association. 2016 Alzheimer's disease facts and figures. Alzheimers Dement 2016; 12: 459-509

[3] Elbaz A, Carcaillon L, Kab S, Moisan F. Epidemiology of Parkinson's disease. Rev Neurol (Paris) 2016; 172: 14-26

[4] Gandhi S, Vaarmann A, Yao Z, Duchen MR, Wood NW, Abramov AY. Dopamine induced neurodegeneration in a PINK1 model of Parkinson's disease. PLoS One 2012; 7: e37564

[5] Han MH, Lee EH, Koh SH. Current opinion on the role of neurogenesis in the therapeutic strategies for Alzheimer disease, Parkinson disease, and ischemic stroke; considering neuronal voiding function. Int Neurourol J 2016; 20: 276-287

[6] Almasieh M, Levin LA. Neuroprotection in glaucoma: animal models and clinical trials. Annu Rev Vis Sci 2017; 3: 91-120

[7] Levin LA, Crowe ME, Quigley HA; Lasker/IRRF Initiative on Astrocytes and Glaucomatous Neurodegeneration Participants. Neuroprotection for glaucoma: Requirements for clinical translation. Exp Eye Res 2017; 157: 34-37

[8] Bagli E, Goussia A, Moschos MM, Agnantis N, Kitsos G. Natural compounds and neuroprotection: mechanisms of action and novel delivery systems. In Vivo 2016; 30: 535-547

[9] Choi DY, Choi H. Natural products from marine organisms with neuroprotective activity in the experimental models of Alzheimer's disease, Parkinson's disease and ischemic brain stroke: their molecular targets and action mechanisms. Arch Pharm Res 2015; 38: 139-170

[10] Shal B, Ding W, Ali H, Kim YS, Khan S. Anti-neuroinflammatory potential of natural products in attenuation of Alzheimer's disease. Front Pharmacol 2018; 9: 548

[11] Velmurugan BK, Rathinasamy B, Lohanathan BP, Thiyagarajan V, Weng CF. Neuroprotective role of phytochemicals. Molecules 2018; 23: E2485

[12] Wenzel T], Klegeris A. Novel multi-target directed ligand-based strategies for reducing neuroinflammation in Alzheimer's disease. Life Sci 2018; 207: 314-322

[13] Ransohoff RM. How neuroinflammation contributes to neurodegeneration. Science 2016; 353: 777-783

[14] Schain M, KreisI WC. Neuroinflammation in neurodegenerative disorders - a review. Curr Neurol Neurosci Rep 2017; 17: 25

[15] Williams PA, Marsh-Armstrong N, Howell GR. Neuroinflammation in glaucoma: a new opportunity. Exp Eye Res 2017; 157: 20-27

[16] Chen WW, Zhang X, Huang WJ. Role of neuroinflammation in neurodegenerative diseases (review). Mol Med Rep 2016; 13: 3391-3396

[17] Camandola S, Mattson MP. NF-kappa B as a therapeutic target in neurodegenerative diseases. Expert Opin Ther Targets 2007; 11: 123-132

[18] Churchward MA, Tchir DR, Todd KG. Microglial function during glucose deprivation: inflammatory and neuropsychiatric implications. Mol Neurobiol 2018; 55: 1477-1487

[19] Tang Y, Le W. Differential roles of M1 and M2 microglia in neurodegenerative diseases. Mol Neurobiol 2016; 53: 1181-1194

[20] Kim EK, Choi EJ. Compromised MAPK signaling in human diseases: an update. Arch Toxicol 2015; 89: 867-882

[21] Weldon DT, Rogers SD, Ghilardi JR, Finke MP, Cleary JP, O'Hare E, Esler WP, Maggio JE, Mantyh PW. Fibrillar beta-amyloid induces microglial phagocytosis, expression of inducible nitric oxide synthase, and loss of a select population of neurons in the rat CNS in vivo. J Neurosci 1998; 18: 2161-2173

[22] Dal Pra I, Chiarini A, Gui L, Chakravarthy B, Pacchiana R, Gardenal E, Whitfield JF, Armato U. Do astrocytes collaborate with neurons in spreading the "infectious" a $\beta$ and Tau drivers of Alzheimer's disease? Neuroscientist 2015; 21: 9-29

[23] Streit W], Mrak RE, Griffin WS. Microglia and neuroinflammation: a pathological perspective. J Neuroinflammation 2004; 1: 14

[24] Boissiere F, Hunot S, Faucheux B, Duyckaerts C, Hauw J], Agid Y, Hirsch EC. Nuclear translocation of NF-kappaB in cholinergic neurons of patients with Alzheimer's disease. Neuroreport 1997; 8: 2849-2852

[25] Valerio A, Boroni F, Benarese M, Sarnico I, Ghisi V, Bresciani LG, Ferrario M, Borsani G, Spano P, Pizzi M. NF-kappaB pathway: a target for preventing beta-amyloid (Abeta)-induced neuronal damage and Abeta42 production. Eur J Neurosci 2006; 23: 1711-1720

[26] Maino B, Paparone S, Severini C, Ciotti MT, D’Agata V, Calissano P, Cavallaro S. Drug target identification at the crossroad of neuronal apoptosis and survival. Expert Opin Drug Discov 2017; 12: 249-259

[27] Radi E, Formichi P, Battisti C, Federico A. Apoptosis and oxidative stress in neurodegenerative diseases. J Alzheimers Dis 2014; 42 (Suppl. 3): S125-S152

[28] Kiraz Y, Adan A, Kartal Yandim M, Baran Y. Major apoptotic mechanisms and genes involved in apoptosis. Tumour Biol 2016; 37: 8471-8486

[29] Obulesu M, Lakshmi M]. Apoptosis in Alzheimer's disease: an understanding of the physiology, pathology and therapeutic avenues. Neurochem Res 2014; 39: 2301-2312

[30] Ghavami S, Shojaei S, Yeganeh B, Ande SR, Jangamreddy JR, Mehrpour M, Christoffersson J, Chaabane W, Moghadam AR, Kashani HH, Hashemi M, Owji AA, Los M]. Autophagy and apoptosis dysfunction in neurodegenerative disorders. Prog Neurobiol 2014; 112: 24-49

[31] Burstein E, Duckett CS. Dying for NF-KB? Control of cell death by transcriptional regulation of the apoptotic machinery. Curr Opin Cell Biol 2003; $15: 732-737$

[32] Kuwana T, Newmeyer DD. Bcl-2-family proteins and the role of mitochondria in apoptosis. Curr Opin Cell Biol 2003; 15: 691-699

[33] Mettang M, Reichel SN, Lattke M, Palmer A, Abaei A, Rasche V, HuberLang M, Baumann B, Wirth T. IKK2/NF-kappaB signaling protects neurons after traumatic brain injury. FASEB ] 2018; 32: 1916-1932

[34] Yu HJ, Koh SH. The role of PI3K/AKT pathway and its therapeutic possibility in Alzheimer's disease. Hanyang Med Rev 2017; 37: 18-24

[35] Heras-Sandoval D, Perez-Rojas JM, Hernandez-Damian J, PedrazaChaverri J. The role of PI3K/AKT/mTOR pathway in the modulation of autophagy and the clearance of protein aggregates in neurodegeneration. Cell Signal 2014; 26: 2694-2701

[36] Caccamo A, Maldonado MA, Majumder S, Medina DX, Holbein W, Magri A, Oddo $S$. Naturally secreted amyloid-beta increases mammalian target of rapamycin (mTOR) activity via a PRAS40-mediated mechanism. J Biol Chem 2011; 286: 8924-8932

[37] Leidal AM, Levine B, Debnath J. Autophagy and the cell biology of agerelated disease. Nat Cell Biol 2018; 20: 1338-1348

[38] Yue Z, Friedman L, Komatsu M, Tanaka K. The cellular pathways of neuronal autophagy and their implication in neurodegenerative diseases. Biochim Biophys Acta 2009; 1793: 1496-1507

[39] Gerónimo-Olvera C, Massieu L. Autophagy as a homeostatic mechanism in response to stress conditions in the central nervous system. Mol Neurobiol 2019. doi:doi:10.1007/s12035-019-1546-x

[40] Singh AK, Kashyap MP, Tripathi VK, Singh S, Garg G, Rizvi SI. Neuroprotection through rapamycin-induced activation of autophagy and PI3K/ Akt1/mTOR/CREB signaling against amyloid-beta-induced oxidative stress, synaptic/neurotransmission dysfunction, and neurodegeneration in adult rats. Mol Neurobiol 2017: 54: 5815-5828 
[41] Xu J, Huai Y, Meng N, Dong Y, Liu Z, Qi Q, Hu M, Fan M, Jin W, Lv P. L-3-nButylphthalide activates Akt/mTOR signaling, inhibits neuronal apoptosis and autophagy and improves cognitive impairment in mice with repeated cerebral ischemia-reperfusion injury. Neurochem Res 2017; 42: 2968-2981

[42] Arthur JSC, Ley SC. Mitogen-activated protein kinases in innate immunity. Nat Rev Immunol 2013; 13: 679-692

[43] Peti W, Page R. Molecular basis of MAP kinase regulation. Protein Sci 2013; 22: 1698-1710

[44] Zhu X, Castellani RJ, Takeda A, Nunomura A, Atwood CS, Perry G, Smith MA. Differential activation of neuronal ERK, JNK/SAPK and p38 in Alzheimer disease: the 'two hit' hypothesis. Mech Ageing Dev 2001; 123 : 39-46

[45] Franco R, Martinez-Pinilla E, Navarro G, Zamarbide M. Potential of GPCRs to modulate MAPK and mTOR pathways in Alzheimer's disease. Prog Neurobiol 2017; 149-150: 21-38

[46] Kandel ER. The molecular biology of memory: CAMP, PKA, CRE, CREB-1, CREB-2, and CPEB. Mol Brain 2012; 5: 14

[47] Yuste JE, Tarragon E, Campuzano CM, Ros-Bernal F. Implications of glial nitric oxide in neurodegenerative diseases. Front Cell Neurosci 2015; 9: 322

[48] Loboda A, Damulewicz M, Pyza E, Jozkowicz A, Dulak J. Role of Nrf2/ HO-1 system in development, oxidative stress response and diseases: an evolutionarily conserved mechanism. Cell Mol Life Sci 2016; 73: 3221-3247

[49] Kerr F, Sofola-Adesakin O, Ivanov DK, Gatliff J, Gomez Perez-Nievas B, Bertrand HC, Martinez P, Callard R, Snoeren I, Cocheme HM, Adcott J, Khericha M, Castillo-Quan JI, Wells G, Noble W, Thornton J, Partridge L. Direct Keap1-Nrf2 disruption as a potential therapeutic target for Alzheimer's disease. PLoS Genet 2017; 13: e1006593

[50] Kim D, Nguyen MD, Dobbin MM, Fischer A, Sananbenesi F, Rodgers JT, Delalle I, Baur JA, Sui G, Armour SM, Puigserver P, Sinclair DA, Tsai LH. SIRT1 deacetylase protects against neurodegeneration in models for Alzheimer's disease and amyotrophic lateral sclerosis. EMBO J 2007; 26: 3169-3179

[51] Bankston AN, Mandler MD, Feng Y. Oligodendroglia and neurotrophic factors in neurodegeneration. Neurosci Bull 2013; 29: 216-228

[52] Longo FM, Massa SM. Small-molecule modulation of neurotrophin receptors: a strategy for the treatment of neurological disease. Nat Rev Drug Discov 2013; 12: 507-525

[53] Mariga A, Mitre M, Chao MV. Consequences of brain-derived neurotrophic factor withdrawal in CNS neurons and implications in disease. Neurobiol Dis 2017; 97: 73-79

[54] L'Episcopo F, Tirolo C, Caniglia S, Testa N, Morale MC, Serapide MF, Pluchino S, Marchetti B. Targeting Wnt signaling at the neuroimmune interface for dopaminergic neuroprotection/repair in Parkinson's disease. J Mol Cell Biol 2014; 6: 13-26

[55] Chen SR, Dai Y, Zhao ], Lin L, Wang Y, Wang Y. A mechanistic overview of triptolide and celastrol, natural products from Tripterygium wilfordii Hook F. Front Pharmacol 2018; 9: 104

[56] Zheng Y, Zhang W], Wang XM. Triptolide with potential medicinal value for diseases of the central nervous system. CNS Neurosci Ther 2013; 19: $76-82$

[57] Zhou ZL, Yang YX, Ding J, Li YC, Miao ZH. Triptolide: structural modifications, structure-activity relationships, bioactivities, clinical development and mechanisms. Nat Prod Rep 2012; 29: 457-475

[58] Hao M, Li X, Feng J, Pan N. Triptolide protects against ischemic stroke in rats. Inflammation 2015; 38: 1617-1623

[59] Zhang B, Song C, Feng B, Fan W. Neuroprotection by triptolide against cerebral ischemia/reperfusion injury through the inhibition of NFkappaB/PUMA signal in rats. Ther Clin Risk Manag 2016; 12: 817-824
[60] Xu P, Li Z, Wang H, Zhang X, Yang Z. Triptolide inhibited cytotoxicity of differentiated PC12 cells induced by amyloid-beta $25-35$ via the autophagy pathway. PLoS One 2015; 10: e0142719

[61] Bai S, Hu Z, Yang Y, Yin Y, Li W, Wu L, Fang M. Anti-inflammatory and neuroprotective effects of triptolide via the NF-kappaB signaling pathway in a rat MCAO model. Anat Rec (Hoboken) 2016; 299: 256-266

[62] Li W, Yang Y, Hu Z, Ling S, Fang M. Neuroprotective effects of DAHP and triptolide in focal cerebral ischemia via apoptosis inhibition and PI3K/ Akt/mTOR pathway activation. Front Neuroanat 2015; 9: 48

[63] Yang Y, Gao K, Hu Z, Li W, Davies H, Ling S, Rudd JA, Fang M. Autophagy upregulation and apoptosis downregulation in DAHP and triptolide treated cerebral ischemia. Mediators Inflamm 2015; 2015: 120198

[64] Lee HF, Lee TS, Kou YR. Anti-inflammatory and neuroprotective effects of triptolide on traumatic brain injury in rats. Respir Physiol Neurobiol 2012; 182: 1-8

[65] Hu G, Gong X, Wang L, Liu M, Liu Y, Fu X, Wang W, Zhang T, Wang X. Triptolide promotes the clearance of alpha-synuclein by enhancing autophagy in neuronal cells. Mol Neurobiol 2017; 54: 2361-2372

[66] Wan B, Hu X, Nie J, Zhou M, Yang B, Li Y, Wen W, Lu C. Effects of triptolide on degeneration of dendritic spines induced by $A \beta 1-40$ injection in rat hippocampus. Neurol Sci 2014; 35: 35-40

[67] Gao JP, Sun S, Li WW, Chen YP, Cai DF. Triptolide protects against 1 methyl-4-phenyl pyridinium-induced dopaminergic neurotoxicity in rats: implication for immunosuppressive therapy in Parkinson's disease. Neurosci Bull 2008; 24: 133-142

[68] Yang F, Wu L, Guo X, Wang D, Li Y. Improved retinal ganglion cell survival through retinal microglia suppression by a chinese herb extract, triptolide, in the DBA/2 J mouse model of glaucoma. Ocul Immunol Inflamm 2013; 21: 378-389

[69] Yang F, Wu L, Li Y, Wang D. Protective effects of triptolide on retina ganglion cells in a rat model of chronic glaucoma. Drug Des Devel Ther 2015; 9: 6095-6107

[70] Xue B, Jiao ], Zhang L, Li KR, Gong YT, Xie JX, Wang XM. Triptolide upregulates NGF synthesis in rat astrocyte cultures. Neurochem Res 2007; 32: 1113-1119

[71] Ning C, Mo L, Chen X, Tu W, Wu J, Hou S, Xu J. Triptolide derivatives as potential multifunctional anti-Alzheimer agents: synthesis and structure-activity relationship studies. Bioorg Med Chem Lett 2018; 28: 689-693

[72] Kishore V, Yarla NS, Bishayee A, Putta S, Malla R, Neelapu NR, Challa S, Das S, Shiralgi Y, Hegde G, Dhananjaya BL. Multi-targeting andrographolide and its natural analogs as potential therapeutic agents. Curr Top Med Chem 2017; 17: 845-857

[73] Yang CH, Yen TL, Hsu CY, Thomas PA, Sheu JR, Jayakumar T. Multi-targeting andrographolide, a novel NF-kappaB inhibitor, as a potential therapeutic agent for stroke. Int J Mol Sci 2017; 18: E1638

[74] Chern CM, Liou KT, Wang YH, Liao JF, Yen JC, Shen YC. Andrographolide inhibits PI3K/AKT-dependent NOX2 and iNOS expression protecting mice against hypoxia/ischemia-induced oxidative brain injury. Planta Med 2011; 77: 1669-1679

[75] Tao L, Zhang L, Gao R, Jiang F, Cao J, Liu H. Andrographolide alleviates acute brain injury in a rat model of traumatic brain injury: possible involvement of inflammatory signaling. Front Neurosci 2018; 12: 657

[76] Chan SJ, Wong WS, Wong PT, Bian JS. Neuroprotective effects of andrographolide in a rat model of permanent cerebral ischaemia. $\mathrm{Br}$ J Pharmacol 2010; 161: 668-679

[77] Yen TL, Chen RJ, Jayakumar T, Lu W], Hsieh CY, Hsu M], Yang CH, Chang CC, Lin YK, Lin KH, Sheu JR. Andrographolide stimulates p38 mitogenactivated protein kinase-nuclear factor erythroid-2-related factor 2heme oxygenase 1 signaling in primary cerebral endothelial cells for definite protection against ischemic stroke in rats. Transl Res 2016; 170: $57-72$ 
[78] Wong SY, Tan MGK, Wong PTH, Herr DR, Lai MKP. Andrographolide induces Nrf2 and heme oxygenase 1 in astrocytes by activating p38 MAPK and ERK. J Neuroinflammation 2016; 13: 251

[79] Du J, Zhang C, Na X, Li A, Zhang Q, Li K, Ding Y. Andrographolide protects mouse astrocytes against hypoxia injury by promoting autophagy and S100B expression. Braz J Med Biol Res 2018; 51: e7061

[80] Rivera DS, Lindsay C, Codocedo JF, Morel I, Pinto C, Cisternas P, Bozinovic $\mathrm{F}$, Inestrosa NC. Andrographolide recovers cognitive impairment in a natural model of Alzheimer's disease (Octodon degus). Neurobiol Aging 2016; 46: 204-220

[81] Serrano FG, Tapia-Rojas C, Carvajal FJ, Hancke J, Cerpa W, Inestrosa NC. Andrographolide reduces cognitive impairment in young and mature AßPPswe/PS-1 mice. Mol Neurodegener 2014; 9: 61

[82] Wang T, Liu B, Zhang W, Wilson B, Hong JS. Andrographolide reduces inflammation-mediated dopaminergic neurodegeneration in mesencephalic neuron-glia cultures by inhibiting microglial activation. J Pharmacol Exp Ther 2004; 308: 975-983

[83] Varela-Nallar L, Arredondo SB, Tapia-Rojas C, Hancke J, Inestrosa NC. Andrographolide stimulates neurogenesis in the adult hippocampus. Neural Plast 2015; 2015: 935403

[84] Dai Y, Chen SR, Chai L, Zhao J, Wang Y, Wang Y. Overview of pharmacological activities of Andrographis paniculata and its major compound andrographolide. Crit Rev Food Sci Nutr 2018; 59 (Suppl. 1): S17-S29

[85] Geng J, Liu W, Xiong Y, Ding H, Jiang C, Yang X, Li X, Elgehama A, Sun Y, Xu Q, Guo W, Gao J. Andrographolide sulfonate improves Alzheimerassociated phenotypes and mitochondrial dysfunction in APP/PS1 transgenic mice. Biomed Pharmacother 2018; 97: 1032-1039

[86] Zhang Z, Lai D, Wang L, Yu P, Zhu L, Guo B, Xu L, Zhou L, Sun Y, Lee SM, Wang Y. Neuroprotective effects of the andrographolide analogue AL-1 in the MPP(+)/MPTP-induced Parkinson's disease model in vitro and in mice. Pharmacol Biochem Behav 2014; 122: 191-202

[87] Javed S, Tariq A, Ahmed T, Budzynska B, Tejada S, Daglia M, Nabavi SF, Sobarzo-Sanchez E, Nabavi SM. Tanshinones and mental diseases: from chemistry to medicine. Rev Neurosci 2016; 27: 777-791

[88] Dai C, Liu Y, Dong Z. Tanshinone I alleviates motor and cognitive impairments via suppressing oxidative stress in the neonatal rats after hypoxicischemic brain damage. Mol Brain 2017; 10: 52

[89] Park JH, Park O, Cho JH, Chen BH, Kim IH, Ahn JH, Lee JC, Yan BC, Yoo KY, Lee $\mathrm{CH}$, Hwang IK, Kwon SH, Lee YL, Won MH, Choi JH. Anti-inflammatory effect of tanshinone $I$ in neuroprotection against cerebral ischemiareperfusion injury in the gerbil hippocampus. Neurochem Res 2014; 39 : $1300-1312$

[90] Jing X, Wei X, Ren M, Wang L, Zhang X, Lou H. Neuroprotective effects of tanshinone I against 6-OHDA-induced oxidative stress in cellular and mouse model of Parkinson's disease through upregulating Nrf2. Neurochem Res 2016; 41: 779-786

[91] Wang S, Jing H, Yang H, Liu Z, Guo H, Chai L, Hu L. Tanshinone I selectively suppresses pro-inflammatory genes expression in activated microglia and prevents nigrostriatal dopaminergic neurodegeneration in a mouse model of Parkinson's disease. J Ethnopharmacol 2015; 164 : 247-255

[92] Chen Y, Wu X, Yu S, Fauzee NJ, Wu J, Li L, Zhao J, Zhao Y. Neuroprotective capabilities of Tanshinone IIA against cerebral ischemia/reperfusion injury via anti-apoptotic pathway in rats. Biol Pharm Bull 2012; 35: 164170

[93] Yin X, Yin Y, Cao FL, Chen YF, Peng Y, Hou WG, Sun SK, Luo Z]. Tanshinone IIA attenuates the inflammatory response and apoptosis after traumatic injury of the spinal cord in adult rats. PLoS One 2012; 7: e38381

[94] Zhu Y, Tang Q, Wang G, Han R. Tanshinone IIA protects hippocampal neuronal cells from reactive oxygen species through changes in autophagy and activation of phosphatidylinositol 3-kinase, protein kinas B, and mechanistic target of rapamycin pathways. Curr Neurovasc Res 2017; 14: $132-140$
[95] Liu L, Zhang X, Wang L, Yang R, Cui L, Li M, Du W, Wang S. The neuroprotective effects of tanshinone IIA are associated with induced nuclear translocation of TORC1 and upregulated expression of TORC1, PCREB and BDNF in the acute stage of ischemic stroke. Brain Res Bull 2010; 82: 228-233

[96] Cai M, Guo Y, Wang S, Wei H, Sun S, Zhao G, Dong H. Tanshinone IIA elicits neuroprotective effect through activating the nuclear factor erythroid 2-related factor-dependent antioxidant response. Rejuvenation Res 2017; 20: 286-297

[97] Yao NW, Lu Y, Shi LQ, Xu F, Cai XH. Neuroprotective effect of combining tanshinone IIA with low-dose methylprednisolone following acute spinal cord injury in rats. Exp Ther Med 2017; 13: 2193-2202

[98] Maione F, Piccolo M, De Vita S, Chini MG, Cristiano C, De Caro C, Lippiello P, Miniaci MC, Santamaria R, Irace C, De Feo V, Calignano A, Mascolo N, Bifulco G. Down regulation of pro-inflammatory pathways by tanshinone IIA and cryptotanshinone in a non-genetic mouse model of Alzheimer's disease. Pharmacol Res 2018; 129: 482-490

[99] Ren B, Zhang YX, Zhou HX, Sun FW, Zhang ZF, Wei Z, Zhang CY, Si DW. Tanshinone IIA prevents the loss of nigrostriatal dopaminergic neurons by inhibiting NADPH oxidase and iNOS in the MPTP model of Parkinson's disease. J Neurol Sci 2015; 348: 142-152

[100] Xu J, Wold EA, Ding Y, Shen Q, Zhou J. Therapeutic potential of oridonin and its analogs: From anticancer and antiinflammation to neuroprotection. Molecules 2018; 23: E474

[101] Owona BA, Schluesener HJ. Molecular insight in the multifunctional effects of oridonin. Drugs R D 2015; 15: 233-244

[102] de Oliveira MR. The dietary components carnosic acid and carnosol as neuroprotective agents: a mechanistic view. Mol Neurobiol 2016; 53: 6155-6168

[103] Wu CR, Tsai CW, Chang SW, Lin CY, Huang LC, Tsai CW. Carnosic acid protects against 6-hydroxydopamine-induced neurotoxicity in in vivo and in vitro model of Parkinson's disease: involvement of antioxidative enzymes induction. Chem Biol Interact 2015; 225: 40-46

[104] James JT, Dubery IA. Pentacyclic triterpenoids from the medicinal herb, Centella asiatica (L.) Urban. Molecules 2009; 14: 3922-3941

[105] Nagoor Meeran MF, Goyal SN, Suchal K, Sharma C, Patil CR, Ojha SK. Pharmacological properties, molecular mechanisms, and pharmaceutical development of asiatic acid: a pentacyclic triterpenoid of therapeutic promise. Front Pharmacol 2018; 9: 892

[106] Krishnamurthy RG, Senut MC, Zemke D, Min J, Frenkel MB, Greenberg EJ, Yu SW, Ahn N, Goudreau J, Kassab M, Panickar KS, Majid A. Asiatic acid, a pentacyclic triterpene from Centella asiatica, is neuroprotective in a mouse model of focal cerebral ischemia. J Neurosci Res 2009; 87: 2541-2550

[107] Lee KY, Bae ON, Serfozo K, Hejabian S, Moussa A, Reeves M, Rumbeiha W, Fitzgerald SD, Stein G, Baek SH, Goudreau J, Kassab M, Majid A. Asiatic acid attenuates infarct volume, mitochondrial dysfunction, and matrix metalloproteinase- 9 induction after focal cerebral ischemia. Stroke 2012; 43: 1632-1638

[108] Lee KY, Bae ON, Weinstock S, Kassab M, Majid A. Neuroprotective effect of asiatic acid in rat model of focal embolic stroke. Biol Pharm Bull 2014; 37: 1397-1401

[109] Xu MF, Xiong YY, Liu JK, Qian J], Zhu L, Gao ]. Asiatic acid, a pentacyclic triterpene in Centella asiatica, attenuates glutamate-induced cognitive deficits in mice and apoptosis in SH-SY5Y cells. Acta Pharmacol Sin 2012; 33: 578-587

[110] Patil SP, Maki S, Khedkar SA, Rigby AC, Chan C. Withanolide A and asiatic acid modulate multiple targets associated with amyloid-beta precursor protein processing and amyloid-beta protein clearance. J Nat Prod 2010; 73: 1196-1202

[111] Zhang X, Wu J, Dou Y, Xia B, Rong W, Rimbach G, Lou Y. Asiatic acid protects primary neurons against C2-ceramide-induced apoptosis. Eur ] Pharmacol 2012; 679: 51-59 
[112] Ahmad Rather M, Justin Thenmozhi A, Manivasagam T, Nataraj J, Essa MM, Chidambaram SB. Asiatic acid nullified aluminium toxicity in in vitro model of Alzheimer's disease. Front Biosci (Elite Ed) 2018; 10: 287-299

[113] Ahmad Rather M, Justin Thenmozhi A, Manivasagam T, Dhivya Bharathi M, Essa MM, Guillemin G]. Neuroprotective role of asiatic acid in aluminium chloride induced rat model of Alzheimer's disease. Front Biosci (Schol Ed) 2018; 10: 262-275

[114] Sirichoat A, Chaijaroonkhanarak W, Prachaney P, Pannangrong W, Leksomboon R, Chaichun A, Wigmore P, Welbat JU. Effects of asiatic acid on spatial working memory and cell proliferation in the adult rat hippocampus. Nutrients 2015; 7: 8413-8423

[115] Xiong $Y$, Ding $\mathrm{H}$, Xu M, Gao J. Protective effects of asiatic acid on rotenone- or $\mathrm{H}_{2} \mathrm{O}_{2}$-induced injury in SH-SY5Y cells. Neurochem Res 2009; 34: 746-754

[116] Nataraj J, Manivasagam T, Justin Thenmozhi A, Essa MM. Neuroprotective effect of asiatic acid on rotenone-induced mitochondrial dysfunction and oxidative stress-mediated apoptosis in differentiated $\mathrm{SH}$ SYS5Y cells. Nutr Neurosci 2017; 20: 351-359

[117] Chao PC, Lee HL, Yin MC. Asiatic acid attenuated apoptotic and inflammatory stress in the striatum of MPTP-treated mice. Food Funct 2016; 7: 1999-2005

[118] Nataraj J, Manivasagam T, Justin Thenmozhi A, Essa MM. Neurotrophic effect of asiatic acid, a triterpene of Centella asiatica against chronic 1methyl 4-phenyl 1,2,3,6-tetrahydropyridine hydrochloride/probenecid mouse model of Parkinson's disease: the role of MAPK, PI3K-AktGSK3 $\beta$ and mTOR signalling pathways. Neurochem Res 2017; 42: 1354-1365

[119] Huang W, Gao F, Hu F, Huang J, Wang M, Xu P, Zhang R, Chen J, Sun X, Zhang $S, W u$ J. Asiatic acid prevents retinal ganglion cell apoptosis in a rat model of glaucoma. Front Neurosci 2018; 12: 489

[120] Rios JL, Manez S. New pharmacological opportunities for betulinic acid. Planta Med 2018; 84: 8-19

[121] Zhang DM, Xu HG, Wang L, Li Y], Sun PH, Wu XM, Wang G], Chen WM, Ye WC. Betulinic acid and its derivatives as potential antitumor agents. Med Res Rev 2015; 35: 1127-1155
[122] Lu Q, Xia N, Xu H, Guo L, Wenzel P, Daiber A, Munzel T, Forstermann U, $\mathrm{Li} \mathrm{H}$. Betulinic acid protects against cerebral ischemia-reperfusion injury in mice by reducing oxidative and nitrosative stress. Nitric Oxide 2011; 24: 132-138

[123] Lu P, Zhang CC, Zhang XM, Li HG, Luo AL, Tian YK, Xu H. Down-regulation of NOX4 by betulinic acid protects against cerebral ischemiareperfusion in mice. J Huazhong Univ Sci Technolog Med Sci 2017; 37: 744-749

[124] Jiao S, Zhu H, He P, Teng J. Betulinic acid protects against cerebral ischemia/reperfusion injury by activating the PI3K/Akt signaling pathway. Biomed Pharmacother 2016; 84: 1533-1537

[125] Kaundal M, Deshmukh R, Akhtar M. Protective effect of betulinic acid against intracerebroventricular streptozotocin induced cognitive impairment and neuronal damage in rats: Possible neurotransmitters and neuroinflammatory mechanism. Pharmacol Rep 2018; 70: 540548

[126] Kaundal M, Zameer S, Najmi AK, Parvez S, Akhtar M. Betulinic acid, a natural PDE inhibitor restores hippocampal cAMP/cGMP and BDNF, improve cerebral blood flow and recover memory deficits in permanent BCCAO induced vascular dementia in rats. Eur J Pharmacol 2018; 832: 56-66

[127] Li C, Zhang C, Zhou H, Feng Y, Tang F, Hoi MPM, He C, Ma D, Zhao C, Lee SMY. Inhibitory effects of betulinic acid on LPS-induced neuroinflammation involve M2 microglial polarization via CaMKKbeta-dependent AMPK activation. Front Mol Neurosci 2018; 11: 98

[128] Ding H, Wang H, Zhu L, Wei W. Ursolic acid ameliorates early brain injury after experimental traumatic brain injury in mice by activating the nrf2 pathway. Neurochem Res 2017; 42: 337-346

[129] Li L, Zhang X, Cui L, Wang L, Liu H, Ji H, Du Y. Ursolic acid promotes the neuroprotection by activating Nrf2 pathway after cerebral ischemia in mice. Brain Res 2013; 1497: 32-39

[130] Caltana L, Rutolo D, Nieto ML, Brusco A. Further evidence for the neuroprotective role of oleanolic acid in a model of focal brain hypoxia in rats. Neurochem Int 2014; 79: 79-87 